\title{
A parametric whole life cost model for offshore wind farms
}

\author{
Mahmood Shafiee $^{1} \cdot$ Feargal Brennan $^{1} \cdot$ Inés Armada Espinosa $^{1}$
}

Received: 29 October 2015 / Accepted: 19 February 2016

(C) Springer-Verlag Berlin Heidelberg 2016

\begin{abstract}
Purpose Life cycle cost (LCC) considerations are of increasing importance to offshore wind farm operators and their insurers to undertake long-term profitable investments and to make electricity generation more price-competitive. This paper presents a cost breakdown structure (CBS) and develops a whole life cost (WLC) analysis framework for offshore wind farms throughout their life span ( $\sim 25$ years).

Methods A combined multivariate regression/neural network approach is developed to identify key cost drivers and evaluate all the costs associated with five phases of offshore wind projects, namely pre-development and consenting (P\&C), production and acquisition (P\&A), installation and commissioning $(I \& C)$, operation and maintenance $(O \& M)$ and decommissioning and disposal (D\&D). Several critical factors such as geographical location and meteorological conditions, rated power and capacity factor of wind turbines, reliability of sub-systems and availability and accessibility of transportation means are taken into account in cost calculations. The O\&M costs (including the cost of renewal and replacement, cost of lost production, cost of skilled maintenance labour and logistics cost) are assessed using the data available in failure databases (e.g. fault logs and O\&M reports) and the data supplied by inspection agencies. A net present value (NPV) approach is used to quantify the current value of future cash flows, and then, a bottom-up estimate of the overall cost is obtained.
\end{abstract}

Responsible editor: Thomas Swarr

Mahmood Shafiee

m.shafiee@cranfield.ac.uk

1 Centre for Offshore Renewable Energy Engineering, Cranfield University, College Road, Bedford MK43 0AL, Befordshire, UK
Results and discussion The proposed model is tested on an offshore 500-MW baseline wind farm project, and the results are compared to experimental ones reported in the literature. Our results indicate that the capital cost of wind turbines and their installation costs account for the largest proportion of WLC, followed by the O\&M costs. A sensitivity analysis is also conducted to identify those factors having the greatest impact on levelized cost of energy (LCOE).

Conclusions The installed capacity of a wind farm, distance from shore and fault detection capability of the condition monitoring system are identified as parameters with significant influence on LCOE. Since the service lifetime of a wind farm is relatively long, a small change in interest rate leads to a large variation in the project's total cost. The presented models not only assist stakeholders in evaluating the performance of ongoing projects but also help the wind farm developers reduce their costs in the medium-long term.

Keywords Capital expenditure (CAPEX) - Levelized cost of energy $(\mathrm{LCOE}) \cdot$ Multivariate regression · Offshore wind farm $\cdot$ Operating expenditure (OPEX) $\cdot$ Whole life cost (WLC)

\section{Introduction}

Offshore wind energy has experienced exponential growth worldwide over the past decade. The cumulative installed capacity of offshore wind power in the European Union (EU) has increased from 622 megawatts (MW) in the year 2004 to $8045 \mathrm{MW}$ at the end of 2014 (Wind Energy Association 2015), representing an annual growth rate of around $29 \%$ (Fig. 1).

Along with the growth of the market for offshore wind energy, the investors and developers need to accurately evaluate the economic feasibility of future projects. Presently, the 
Fig. 1 Cumulative installed capacity of offshore wind energy in the EU during 2004-2014

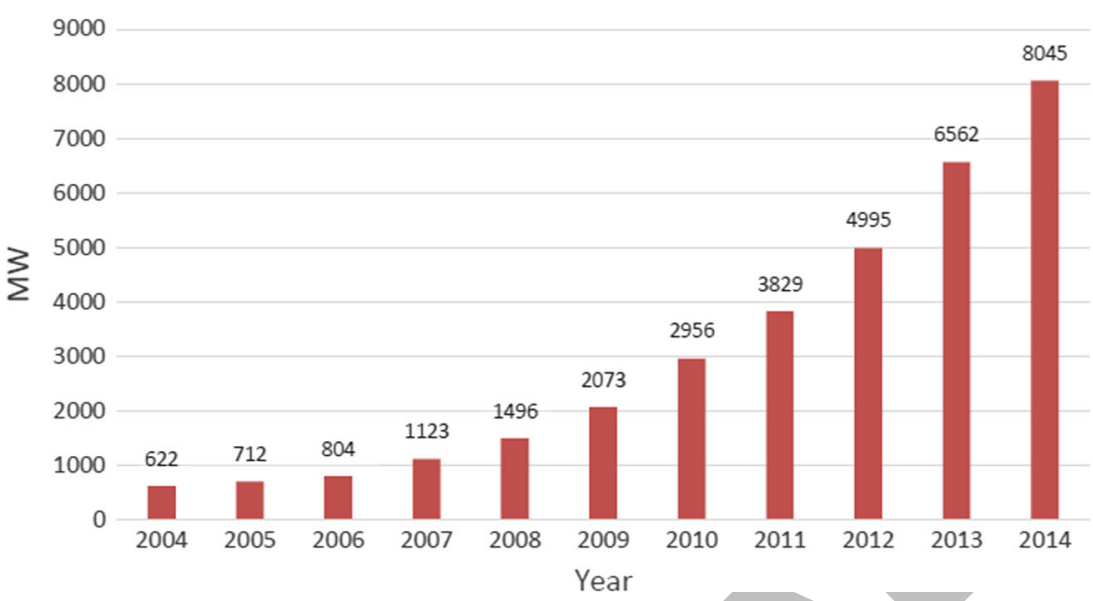

cost per kilowatt hour of electricity generated by onshore wind turbines is approximately 8.66 cents, while offshore wind is estimated to cost $22.15 \varnothing / \mathrm{kwh}$ (i.e. 2.55 times more expensive than onshore wind) (U.S. Energy Information Administration 2014). Even though the expensive foundations and transmission system as well as the relatively high cost of offshore installations are major reasons behind this extra cost, the impact of some critical factors such as high failure rate of subassemblies, deep-water installations, late delivery of spare parts, limited availability of transport vessels and weatherdependent access to offshore locations has yet to be properly quantified. For this purpose, the capital expenditure (CAPEX), operating expenditure (OPEX) and the levelized cost of energy (LCOE) must be calculated by considering all the costs over the project's life cycle, from the predevelopment to the decommissioning phase (Shafiee 2015a).

The concept of life cycle cost (LCC) analysis was first introduced by the U.S. Department of Defense (DoD) in the 1970s. Since then, it has been applied to a wide variety of projects in a range of industry sectors, including construction, energy, transport, manufacturing and healthcare (Fuller and Peterson 1996). LCC analysis is defined as a process of evaluating the economic performance of a system or a project over its entire life span. The usefulness of LCC analysis tools mainly lies in their ability to identify, analyse, evaluate and reduce the overall cost of key operations. The results of an LCC analysis can be used to enhance the knowledge of managers about the economic life of assets and also to assist the stakeholders in making appropriate investment decisions.

The LCC modelling and analysis of wind power systems have received significant attention during the last few years as a result of growing investment in new wind projects (Davidsson et al. 2012). Several organizations such as the European Wind Energy Association (EWEA), National Renewable Energy Laboratory (NREL) and International Renewable Energy Agency (IRENA) publish regular statistical reports on wind power generation costs (e.g. see Krohn et al. 2009; Tegen et al. 2013; Renewable Energy Agency
2012). Kaiser and Snyder (2012) addressed all aspects concerning the installation and decommissioning phases of offshore wind projects and then developed a methodological framework to assess the related costs. Nilsson and Bertling (2007) and Nordahl (2011) have also studied the LCC of wind power systems; however, these works mainly focus on evaluating the costs that are incurred over the operation and maintenance (O\&M) phase.

Recently, there has been a particular interest in LCC analysis of offshore wind turbines. A comprehensive methodology for economic analysis of the floating offshore wind turbines was recently presented in CastroSantos and Diaz-Casas (2014). The authors proposed a cost breakdown structure (CBS) to identify various cost elements involved in six phases of development of floating offshore wind turbine technologies, namely definition, design, manufacturing, installation, exploitation and dismantling. In another study, Myhr et al. (2014) presented an analysis model to compare the LCOE of five floating wind turbine concepts, including SparBuoy (Hywind II), Tension-Leg-Spar (SWAY), SemiSubmersible (WindFloat), Tension-Leg-Wind-Turbine (TLWT) and Tension-Leg-Buoy (TLB). Thomson and Harrison (2015) estimated the life cycle costs and carbon emissions of offshore wind technologies and associated infrastructure during four life stages: manufacturing, transport and installation, operation and maintenance, and dismantling and disposal.

Madariaga et al. (2012) point out that the development of a realistic and accurate method for LCC analysis of large-scale offshore wind farms with taking into account all important aspects of the project is a very complex task. To the best of the authors' knowledge, there is no universal and integrated framework for LCC modelling and analysis of offshore wind farms enabling to compare different projects on a same basis. Therefore, it is crucial to develop an enterprise cost analysis model not only to assist stakeholders in evaluating the 
performance of ongoing projects but also to help decisionmakers undertake long-term profitable investments and make offshore wind power generation price-competitive with onshore production as well as with other sources of renewable energy (e.g. geothermal, biomass).

This paper aims to present a whole life cost (WLC) analysis framework for large-scale offshore wind farms throughout their life span ( 25 years). The key cost drivers of offshore wind projects in five phases of pre-development and consenting $(\mathrm{P} \& \mathrm{C})$, production and acquisition $(\mathrm{P} \& \mathrm{~A})$, installation and commissioning (I\&C), operation and maintenance (O\&M), and decommissioning and disposal (D\&D) are identified, and a mathematical tool is proposed to evaluate the associated costs. Several critical factors such as geographical location and meteorological conditions, rated power and capacity factor of wind turbines, reliability of sub-assemblies, and availability and accessibility of transportation means are taken into consideration in cost calculations. A net present value (NPV) approach is also used to quantify the current value of future cash flows, and then, a bottom-up estimate of the overall cost is obtained. While comparing the results obtained from this study with other research, it is concluded that the model is capable of accurately estimating the LCC as it captures the trend in experimental data quite well. The results of our analysis can be used as a guideline to reduce the costs of offshore wind projects, thanks to a better understanding of how key parameters influence the overall cost.

The rest of this paper is organized as follows. In Section 2, the whole life cycle cost analysis framework is presented. In Section 3, the model is applied to an offshore baseline wind farm project. In Section 4, the results obtained from the model are presented and a sensitivity analysis is conducted. Section 5 concludes our study and suggests topics for future research.

\section{Proposed framework}

In this section, a "parametric" whole life cost analysis framework for offshore wind farms with fixed-bottom wind turbine technology is presented. The developed model is based on a combined multivariate regression/neural network approach in which the cost experience of completed/ongoing projects provides a baseline for estimating the costs of future offshore wind projects.

Based on the extensive literature review conducted for this study, the cost drivers of offshore wind projects mainly fall into five categories: pre-development and consenting (P\&C), production and acquisition ( $\mathrm{P} \& \mathrm{~A})$, installation and commissioning (I\&C), operation and maintenance (O\&M) and decommissioning and disposal (D\&D) (Fig. 2). These cost categories are then subdivided into their constituent elements, and a database/spreadsheet is built for each cost element. In order to account for the time value of money, all future costs are discounted to their current value using an appropriate discount rate. For this purpose, the cash flows arising at different points in time are converted to a common reference point (i.e. present time) by using the following net present value (NPV) formula (Levitt et al. 2011):

$\operatorname{NPV}(d, N)=\sum_{t=0}^{N} C_{t} /(1+d)^{t}$,

where $C_{t}, d$ and $N$ represent, respectively, the cash flow at time $t$, annual interest rate and the number of years in which the investment takes place. In what follows, the cost categories are described in detail.

\subsection{Pre-development and consenting}

The development of an offshore wind farm normally begins around 5 years before the time when the installation is executed. From the first idea to the start of the project, many procedures, studies and paperwork must be accomplished to ensure the technical/economical feasibility. These costs are related to project management $\left(C_{\text {projM }}\right)$, legal authorization $\left(C_{\text {legal }}\right)$, the conducted surveys ( $\left.C_{\text {surveys }}\right)$, engineering activities $\left(C_{\text {eng }}\right)$ and contingencies $\left(C_{\text {contingency }}\right)$. Thus,

$C_{\mathrm{P} \& \mathrm{C}}=C_{\text {projM }}+C_{\text {legal }}+C_{\text {surveys }}+C_{\text {eng }}+C_{\text {contingency }}$.

\subsubsection{Project management}

The project management tasks include all administrative services, pre-feasibility studies, financing, tendering process, internal controlling systems, and negotiating with subcontractors. The total cost of project management is usually expressed as a percentage of the CAPEX. According to Offshore Design Engineering Ltd. (2007), this percentage is estimated to be around $3 \%$, i.e.

$C_{\text {projM }}=0.03 \times$ CAPEX

\subsubsection{Legal authorization}

In order to execute an offshore wind farm development, an authorization by the government or a regulatory body is required. In some studies, the legal authorization process is considered as a part of project management. But since the permitting process is significantly different from country to country, we have separated them from each other in this paper. During the authorization process, appropriate documents are provided and some local authorities are contacted and asked for 


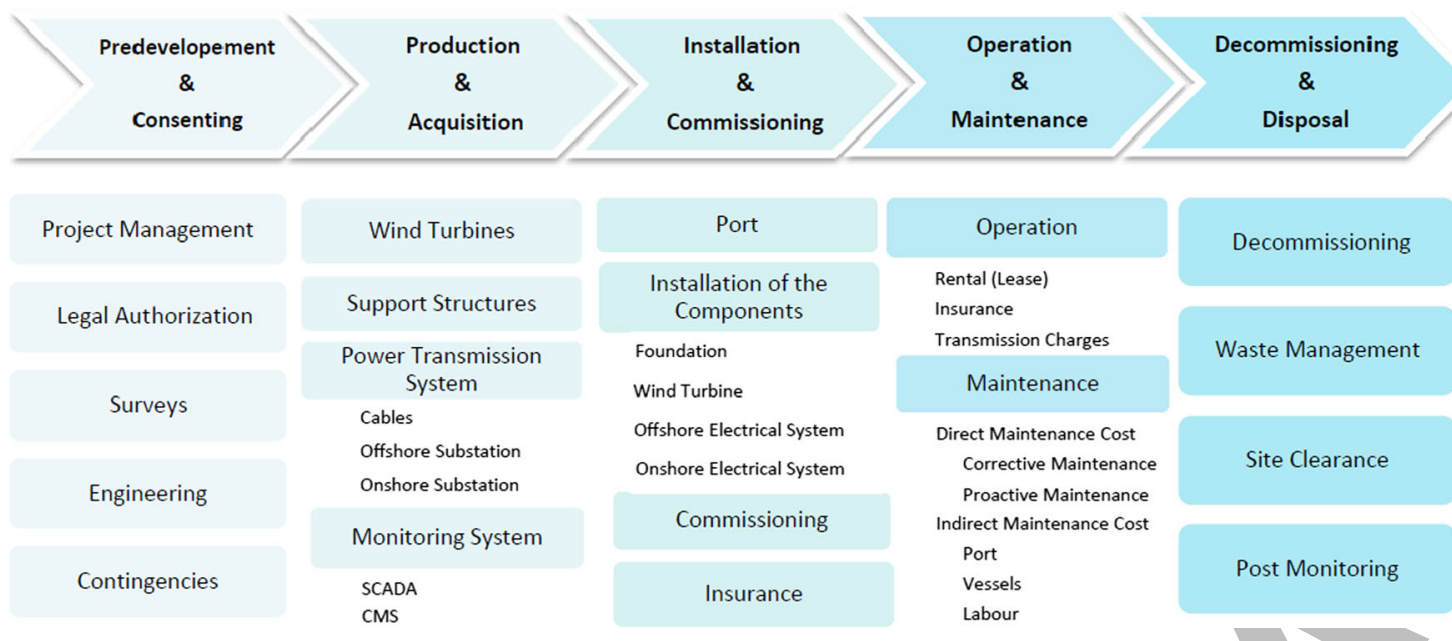

Fig. 2 Cost breakdown structure (CBS) for offshore wind farms

approval. The cost of legal authorization is estimated to be approximately $0.13 \%$ of the CAPEX (The Crown Estate 2010; Howard 2012). Then,

$C_{\text {legal }} \cong 0.0013 \times$ CAPEX .

\subsubsection{Surveys}

In order to evaluate the feasibility of offshore wind projects, some site-specific surveys need to be conducted. The type of surveys conducted usually varies according to the kind of information required. Currently, four types of surveys are used for offshore wind farm developments: environmental, coastal processes, seabed and metocean conditions. So, the cost of surveying over the $\mathrm{P} \& \mathrm{C}$ phase is given by

$C_{\text {surveys }}=C_{\text {surv-EN }}+C_{\text {surv-CP }}+C_{\text {surv-SB }}+C_{\text {surv-MO }}$,

where $C_{\text {surv-EN }}, C_{\text {surv-CP }}$ and $C_{\text {surv-SB }}$ represent the cost of carrying out, respectively, environmental, coastal processes and seabed surveys and all depend on the wind farm's installed capacity (IC), whereas $C_{\text {surv-MO }}$ represents the cost of metocean studies and is considered to be constant regardless of the number of wind turbines being built.

\subsubsection{Engineering}

Once the project is approved and the final investment decision is made, a multidisciplinary team is constituted to design the offshore wind farm. Some of the activities that are undertaken during this stage include structural design and selection of foundation, design of wind farm layout and design of electrical system and grid connection. The engineering cost comprises the costs associated with main engineering activities
( $\left.C_{\text {eng-main }}\right)$ and design verification process $\left(C_{\text {eng-verif }}\right)$ (Offshore Design Engineering Ltd. 2007), i.e.

$$
C_{\text {eng }}=C_{\text {eng-main }}+C_{\text {eng-verif }} \text {. }
$$

The cost of main engineering activities depends on the project size and is modelled as a function of the wind farm's installed capacity (Castro-Santos and Diaz-Casas 2014). In this paper, we assume that $C_{\text {eng-main }}$ is the sum of a fixedbase $\operatorname{cost}\left(C_{\text {base }}\right)$ and the term described by an increasing linear function of the installed capacity as follows:

$C_{\text {eng-main }}=C_{\text {base }}+C_{\text {eng-unit }} \times \mathrm{IC}$.

\subsubsection{Contingencies}

The contingency cost accounts for unpredictable annual expenses and allowance for replacement of the most expensive components subject to catastrophic failure. The contingency cost is considered a certain percentage (around $10 \%$ ) of the CAPEX (Howard 2012), i.e.

$C_{\text {contingency }} \cong 0.1 \times$ CAPEX.

\subsection{Production and acquisition}

The production and acquisition (P\&A) cost includes all costs associated with the procurement of wind turbines $\left(C_{\mathrm{WT}}\right)$, the support structure or foundation $\left(C_{\mathrm{SS}}\right)$, the power transmission system $\left(C_{\mathrm{PTS}}\right)$ and the monitoring system ( $\left.C_{\text {monitoring }}\right)$. Then,

$C_{\mathrm{P \& A}}=C_{\mathrm{WT}}+C_{\mathrm{SS}}+C_{\mathrm{PTS}}+C_{\text {monitoring }}$. 


\subsubsection{Wind turbines}

The total cost of procurement of wind turbines is described as a function of the number of wind turbines installed in the wind farm $\left(N_{\mathrm{WT}}\right)$ as follows:

$C_{\mathrm{WT}}=\left(C_{\mathrm{wt}-\mathrm{mat}}+C_{\mathrm{wt} t \text { trans }}\right) \times N_{\mathrm{WT}}$,

where $C_{\text {wt-mat }}(£)$ represents the material costs for a wind turbine with all its constituent sub-systems and $C_{\mathrm{wt}-\text { trans }}(\mathfrak{f})$ is the transportation cost of a wind turbine from the manufacturing location to the installation site. The cost of materials depends on the nominal wind turbine power rating (PR). Using a logarithmic regression model on the available dataset containing prices of various wind turbines with rated power between 2 and $5 \mathrm{MW}$ (Fig. 3), the material cost for a wind turbine is modelled by

$C_{\mathrm{wt}-\mathrm{mat}}=3,000,000 \times \operatorname{Ln}(\mathrm{PR})-662,400$.

The transportation cost of a wind turbine is calculated by multiplying the average vessel-day required $\left(N_{\mathrm{v}-\mathrm{d}}\right)$ by the fixed daily rate of hiring a vessel (Vr), i.e.

$C_{\mathrm{wt}-\text { trans }}=N_{\mathrm{v}-\mathrm{d}} \times \mathrm{Vr}$.

\subsubsection{Support structures}

The cost of a support structure is divided into two parts, one for material cost $\left(C_{\text {ss-mat }}\right)$ and another one for transport and installation $\left(C_{\mathrm{ss} \text {-trans }}\right)$. Thus, the total cost of procurement of support structures is given by

$$
C_{\mathrm{SS}}=\left(C_{\mathrm{ss}-\mathrm{mat}}+C_{\mathrm{ss}-\text { trans }}\right) \times N_{\mathrm{WT}} .
$$

Nielsen (2003) showed that the cost of material for a wind turbine support structure does not yary much from one type to another, but it increases by $2 \%$ for each metre increase in water depth (WD) and by $80 \%$ for each unit increase in load factor. Dicorato et al. (2011) modelled the average cost of materials used for a support structure by

$$
\begin{aligned}
C_{\text {ss-mat }}= & 339,200 \times \mathrm{PR} \times(1+0.02 \times(\mathrm{WD}-8)) \\
& \times\left[1+0.8 \times 10^{-6}\left(h\left(\frac{d}{2}\right)^{2}-10^{5}\right)\right],
\end{aligned}
$$

where $h$ and $d$ represent, respectively, the hub height and the rotor diameter of a wind turbine in metres. For the transportation cost of support structures, Eq. 12 can similarly be applied.

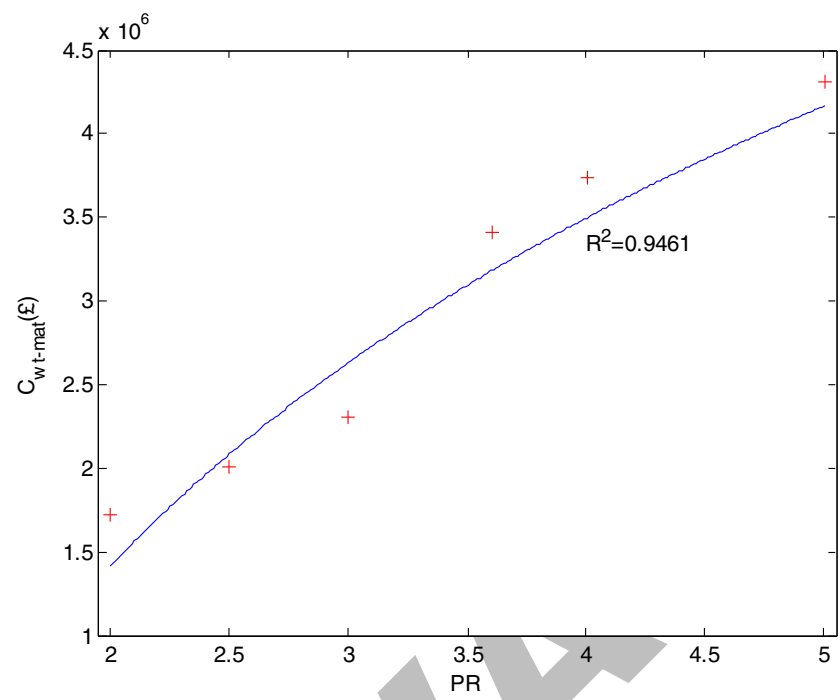

Fig. 3 A logarithmic model for cost of materials used in a wind turbine (root mean square of error $\cong £ 223,000$ )

\subsubsection{Power transmission system}

The power transmission system is composed of a number of cables that connect wind turbines to the grid and onshore/ offshore substations. So, the cost of the power transmission system is given by

$$
C_{\mathrm{PTS}}=C_{\text {cables }}+C_{\text {of-subs }}+C_{\text {on-subs }} \text {. }
$$

The cables used for power transmission in offshore wind farms are divided into three parts: inter-array $(i=1)$, export $(i=2)$ and onshore $(i=3)$. The cable cost for each part can be calculated by the product of the price of unit length of cable ( $\left.C_{\text {cable-unit }}\right)$, the number of lines ( $\left.N_{\text {lines }}\right)$ and the average length of each line $(L)$. Moreover, J-tube seals, passive seals, bend restrictors, stiffeners or cable mats are required to protect the cables at some locations. So,

$C_{\text {cables }}=\sum_{i=1}^{3} C_{\text {cable-unit } i} \times L_{i} \times N_{\text {lines } i}+C_{\text {protection }}$,

where $C_{\text {protection }}(£)$ represents the cable protection cost which varies depending on the number of wind turbines installed. Offshore substations are normally used when the wind farm's installed capacity is larger than $100 \mathrm{MW}$ and/ or the wind farm is very far from shore. These substations are designed specifically for each wind farm project with taking into account several factors such as the distance to shore, water depth and, more importantly, the installed capacity. In this study, a linear regression model is trained on our dataset which consists of prices of substations for various wind farms whose capacities range from 300 to $1500 \mathrm{MW}$ and supplemented by data presented in Myhr 


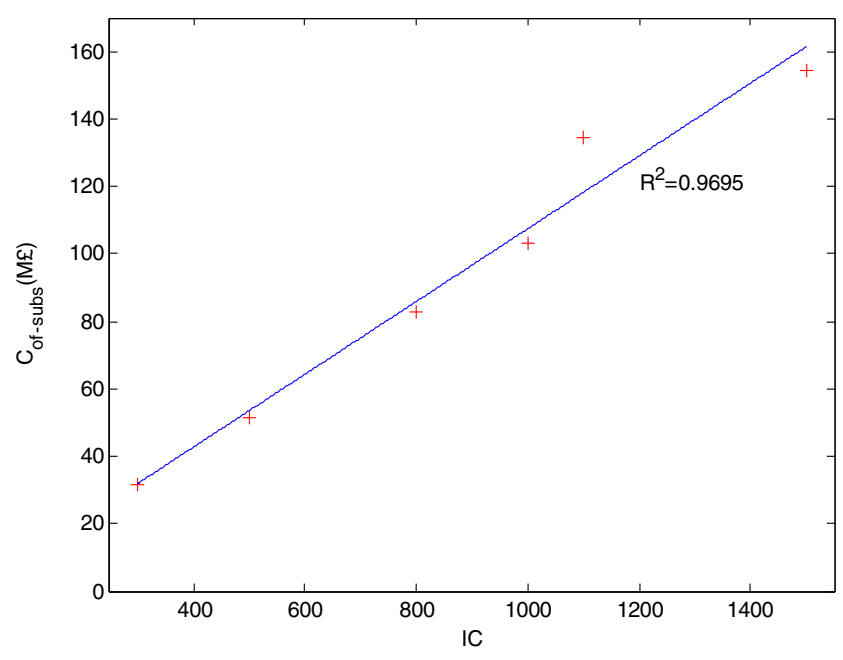

Fig. 4 A linear regression model for offshore substation cost

et al. (2014). The cost of an offshore substation is estimated as follows (Fig. 4):

$C_{\text {of-subs }}=583,300+107,900 \times \mathrm{IC}$, for $I C \geq 100 \mathrm{MW}$.

Finally, the cost of an onshore substation is assumed to be around half of the cost of an offshore substation (CastroSantos and Diaz-Casas 2014; The Crown Estate 2010), i.e.

$C_{\text {on-subs }} \cong C_{\text {of-subs }} / 2$.

\subsubsection{Monitoring system}

Currently, a large number of sensors and control devices are installed throughout the offshore wind farms to collect condition data (e.g. sea-state data, deterioration data). The collected information is frequently transferred to the supervisory control and data acquisition (SCADA) system and is stored in databases. The system analysts use these condition data to schedule the inspection and maintenance tasks. The cost of SCADA and condition monitoring systems (CMSs) for an offshore wind farm depends on the number of wind turbines installed (Tavner 2013). Then,

$C_{\text {monitoring }}=\left(C_{\mathrm{SCADA}}+C_{\mathrm{CMS}}\right) \times N_{\mathrm{WT}}$,

where $C_{\mathrm{SCADA}}$ and $C_{\mathrm{CMS}}$ represent the cost of, respectively, SCADA and CMS for a wind turbine.

\subsection{Installation and commissioning}

The installation and commissioning (I\&C) phase involves all activities related to the construction of offshore wind farms. The costs incurred at this stage include those related to port $\left(C_{\text {I\&C-port }}\right)$, installation of the components $\left(C_{\text {I\&C-comp }}\right)$, commissioning of the wind turbines and electrical system $\left(C_{\text {comm }}\right)$, and the construction insurance $\left(C_{\mathrm{I} \& \text { C-ins }}\right)$. Hence,

$C_{\mathrm{I} \& \mathrm{C}}=C_{\mathrm{I} \& \mathrm{C}-\text { port }}+C_{\mathrm{I} \& \mathrm{C}-\mathrm{comp}}+C_{\mathrm{comm}}+C_{\mathrm{I} \& \mathrm{C} \text {-ins }}$.

\subsubsection{Port}

The port plays a key role in the supply chain management of offshore wind farms. Annual fees must be paid to local authorities for the use of port infrastructure, quayside docking, and the permission for crane use (Maples et al. 2013), which all are assumed to be fixed and known in this paper $\left(C_{\text {port-use }}\right)$. In addition, the annual payments to wind farm labourers who carry out project activities (e.g. pre-assembling the components) must be taken into account $\left(C_{\text {port-labour }}\right)$. Then,

$C_{\mathrm{I} \& \mathrm{C} \text {-port }}=C_{\text {port-use }}+C_{\text {port-labour }}$.

The port labour cost is calculated by multiplying the average labour-day required $\left(N_{1-\mathrm{d}}\right)$ by the fixed daily labour rate $(\mathrm{Lr})$, i.e.

$C_{\text {port-labour }}=N_{\text {l-d }} \times$ Lr.

\subsubsection{Installation of the components}

Several operations need to be performed during the installation process of an offshore wind farm project. The cost of installation, according to the type of components installed, is divided into four parts: foundation, wind turbine, and offshore and onshore electrical systems. Then,

$$
\begin{aligned}
C_{\mathrm{I} \& \mathrm{C}-\text { comp }}= & C_{\mathrm{I} \& \mathrm{C}-\mathrm{f}}+C_{\mathrm{I} \& \mathrm{C}-\mathrm{wt}}+C_{\mathrm{I} \& \mathrm{C}-\text { ofsubs }} \\
& +C_{\mathrm{I} \& \mathrm{C}-\text { onsubs } .}
\end{aligned}
$$

In all the above cost elements, the costs related to hiring chartered ships and technicians are also included. In addition, preparation of the seabed is often required prior to installation of the foundations. An offshore electrical system is composed of both the array and the export cables whose associated costs are a function of the total length (distance).

\subsubsection{Commissioning}

Before starting up an offshore wind farm, the wind turbines, electrical systems, SCADA and CMSs are tested to detect early failures and improve reliability (Dinmohammadi and Shafiee, 2013). The cost of commissioning $\left(C_{\text {comm }}\right)$ mainly consists of the costs associated with hiring vessels and crew members which can be calculated similarly as given in Eqs. 12 and 22. 


\subsubsection{Insurance}

During the installation and commissioning phase, many unexpected events (such as environmental damages) may take place. In order to minimize the negative impacts of these events, various insurance packages are offered to wind farm owners. The cost of these packages often varies in accordance with the capacity of the offshore wind farm and is calculated by

$C_{\mathrm{I} \& \mathrm{C} \text {-ins }}=C_{\text {ins-unit }} \times \mathrm{IC}$,

where $C_{\text {ins-unit }}$ represents the insurance cost per unit installed capacity (MW).

\subsection{Operation and maintenance}

The operation and maintenance (O\&M) cost of an offshore wind farm is divided into two parts, one for the operational expenses $\left(C_{\mathrm{O}}\right)$ and the other one for the maintenance expenses $\left(C_{\mathrm{M}}\right)$. Thus,

$C_{\mathrm{O \& M}}=C_{\mathrm{O}}+C_{\mathrm{M}}$

\subsubsection{Operation}

The operational expenses of an offshore wind project include the rental/lease payments $\left(C_{\text {rent }}\right)$, the insurance costs $\left(C_{\mathrm{O} \& \mathrm{M}-}\right.$ ins) and the transmission charges $\left(C_{\text {transmission }}\right)$. Thus,

$C_{\mathrm{O}}=C_{\text {rent }}+C_{\mathrm{O} \& \mathrm{M}-\mathrm{ins}}+C_{\text {transmission }}$.

Rental (lease) The wind farm developers have to pay fees to local authorities and landowner for the seabed rentals. The amount of these fees can vary from country to country, but it is generally expressed as a fraction of the wind farm's revenue. We assume that rental charges are calculated using the following equation:

$C_{\text {rent }}=\ell \times E \times P_{E}$,

where $0<\ell<1$ is the rental percentage, and $E(\mathrm{MWh})$ and $P_{E}$ $(£ / \mathrm{MWh})$, respectively, represent the amount of energy and the average price per unit of energy produced by the wind farm.

Insurance The operational insurance packages are contracted in order to secure the offshore wind infrastructures against design faults, collision damages or substation outages. The cost of insurance packages depends on wind farm capacity and can be calculated similarly as given in Eq. 24 .
Transmission charges An annual fee has to be paid to the authorities who are in charge of the national electrical grid. The transmission charges are generally determined according to the capacity of the wind farm. Thus,

$C_{\text {transmission }}=C_{\text {transmission-unit }} \times \mathrm{IC}$,

where $C_{\text {transmission-unit }}$ represents the transmission charges per unit installed capacity (MW).

\subsubsection{Maintenance}

The maintenance activities aim to maximize the availability of offshore wind turbines while minimizing the costs associated with random failures. The maintenance costs can be categorized into two types, $\operatorname{direct}\left(C_{\mathrm{M} \text {-direct }}\right)$ and indirect $\left(C_{\mathrm{M} \text {-indirect }}\right)$. Then,

$C_{\mathrm{M}}=C_{\mathrm{M} \text {-direct }}+C_{\mathrm{M} \text {-indirect }}$.

Direct maintenance cost Direct maintenance cost consists of the costs related to transport of failed components, maintenance technicians who carry out the repair/replacement actions and all consumables and spare parts required for wind farm maintenance. In general, the maintenance strategies for offshore wind farms are categorized into two classes: corrective maintenance (CM) and proactive maintenance (ProM) (Fig. 5). The main difference between these two classes is that the former is carried out after the failure of the system, while the latter takes place prior to any failure (i.e. before a failure occurs) (Shafiee 2015b). The cost of a CM action varies depending on the type of component being failed. Let $n$ represent the number of components in a wind turbine system and denote by $C_{\mathrm{CM} j}$ the cost of performing a CM action on component $j$, for any $j \in\{1,2, \ldots, n\}$. Then,

$C_{\mathrm{CM} j}=C_{\text {trans } j}+C_{\text {labour } j}+C_{\text {consum } j}$,

where $C_{\text {trans } j}, C_{\text {labour } j}$ and $C_{\text {consum } j}$ represent, respectively, the transportation cost, maintenance labour cost and consumables cost. The cost of consumables is assumed to be fixed in this study, but the expected costs of transport and maintenance technicians are calculated using the following equations (Shafiee and Dinmohammadi 2014):

$C_{\text {trans } j}=2 d \times$ tc $_{j}$,

$\mathrm{C}_{\text {labour } j}=\mathrm{N}_{\mathrm{l}-\mathrm{d} j} \times \mathrm{Lr}$,

where $d(\mathrm{~km})$ represents the distance between the wind farm and the repair shop, $\mathrm{tc}_{j}(£ / \mathrm{km})$ is the transportation cost per unit distance, $N_{1-\text { d } j}$ represents the average labour-day required for maintenance of component $j$ and $\operatorname{Lr}(£ /$ day) is the fixed daily labour rate. In order to reduce the costs of CM, two proactive maintenance strategies, namely scheduled 


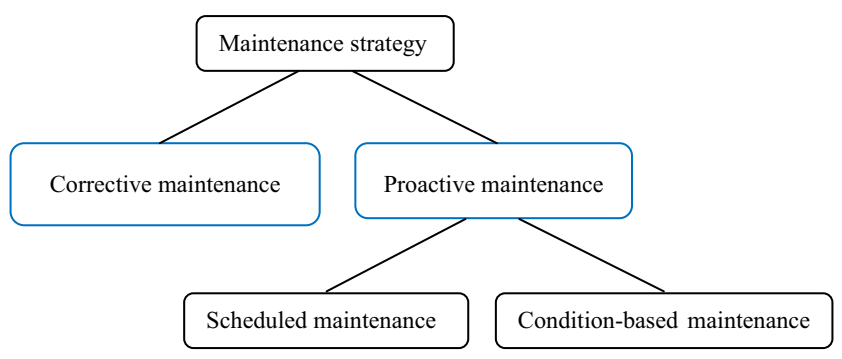

Fig. 5 Wind farm maintenance strategies

maintenance (SM) and condition-based maintenance (CBM), are employed by wind farm managers (Shafiee 2015c). Under $\mathrm{SM}$, the repair tasks are undertaken at predetermined regular intervals, but CBM activities are initiated in response to a specific system condition (e.g. temperature, vibration, noise, lubrication and corrosion) (Shafiee and Finkelstein 2015).

Let $\lambda_{j}$ represent the annual failure rate of component $j$ and $0<P_{d}<1$ be the probability that an event can be detected at a reasonably long time ahead of failure occurrence. Thus, the annual cost for individual maintenance of the wind turbine components can be expressed by

$C_{\mathrm{M} \text {-direct }}=\left(1-P_{d}\right) \times \sum_{j=1}^{n} \lambda_{j} C_{\mathrm{CM}_{j}}+P_{d} \times \sum_{j=1}^{n} \lambda_{j} C_{\mathrm{SM}_{j}}$,

where $C_{\mathrm{SM} j}$ represents the direct cost corresponding to a scheduled maintenance of the component $j$ and is less than the cost of failure, i.e. $C_{\mathrm{SM} j}<C_{\mathrm{CM} j}$ for any $j \in\{1,2, \ldots, n\}$. From Eq. 33, it can be seen that the detection capability of the monitoring system plays a key role in reducing the annual direct maintenance costs. The detection capability can be improved through using new monitoring techniques such as acoustic emission, ultrasonic testing, strain measurement, radiographic inspection, thermography and signal processing methods (Márquez et al. 2012).

Indirect maintenance cost Indirect maintenance cost consists of the cost of activities that are undertaken to maintain the direct effort involved in providing repair services. Indirect costs may be either fixed or variable. Independently from the number of maintenance tasks to be carried out, port fees must be paid for spare parts storage and quayside facilities. A number of vessels also have to be hired for the maintenance. Besides this, various operations (e.g. weather forecasting, scheduling of repair tasks) should be accomplished onshore to coordinate the maintenance activities (Garrad Hassan 2013). Hence, the indirect maintenance cost is given by

$C_{\mathrm{M} \text {-indirect }}=C_{\text {ind-port }}+C_{\text {ind-ves }}+C_{\text {ind-labour }}$,

where $C_{\text {ind-port }}, C_{\text {ind-ves }}$ and $C_{\text {ind-labour }}$ represent, respectively, the port fees, vessel hiring costs and maintenance labour costs.

\subsection{Decommissioning and disposal}

The decommissioning and disposal is the final stage of a wind project life cycle, whose procedure is the reverse of the installation and commissioning (I\&C) process. The wind turbines at the end of their anticipated operational life are decommissioned, the wind farm equipment depending on the chosen waste management strategy are either removed or recycled, the offshore site is cleared and, lastly, some postdecommissioning monitoring activities are performed. Then,

$C_{\mathrm{D} \& \mathrm{D}}=C_{\mathrm{decom}}+C_{\mathrm{WM}}+C_{\mathrm{SC}}+C_{\mathrm{post} \mathrm{M}}$,

where $C_{\text {decom }}, C_{\mathrm{WM}}, C_{\mathrm{SC}}$ and $C_{\mathrm{postM}}$ represent the costs associated with, respectively, decommissioning, waste management, site clearing and post-monitoring.

\subsubsection{Decommissioning}

The decommissioning cost consists of the costs associated with port preparation $\left(C_{D \& D-p o r t}\right)$ and removal operations $\left(C_{\text {remov }}\right)$. Then, the decommissioning cost is given by

$C_{\text {decom }}=C_{\text {D\&D-port }}+C_{\text {remov }}$

The cost of port preparation, $C_{\mathrm{D} \& \mathrm{D}-\text { port }}$, can be calculated similarly as given in Eqs. 21 and 22. For the cost of removal operations, Eq. 12 can be applied considering that less specialized vessels are required for decommissioning activities.

\subsubsection{Waste management}

The waste management strategy determines how the wind farm elements will be disposed. The main disposal options available are as follows: reuse, recycle, incineration with energy recovery and disposal in a landfill site (Department of Energy and Climate Change DECC 2011). Independently from the waste treatment option chosen, the materials must be first processed into smaller pieces and then transported to predetermined locations which incur the costs $C_{\mathrm{W} \text {-proc }}$ and $C_{\mathrm{W} \text {-trans, }}$, respectively. A fixed fee has also to be paid when the materials are taken to a landfill $\left(C_{\text {landfill }}\right)$. Then,

$C_{\mathrm{WM}}=C_{\mathrm{W}-\text { proc }}+C_{\mathrm{W} \text {-trans }}+C_{\text {landfill }}-\mathrm{SV}$,

where SV (£) represents the salvage (residual) value of the decommissioned assets.

Waste processing After decommissioning wind turbines, the waste materials must be processed subject to strict quality controls. The cost of waste processing varies in accordance 
with the complexity and size of components. In this paper, $C_{\text {W-proc }}$ is modelled as a function of the total weight of waste material being treated. Hence,

$C_{\mathrm{W} \text {-proc }}=\sum_{j=1}^{n} W_{j} \times C_{\text {proc-unit }}$,

where $C_{\text {proc-unit }}(£ /$ ton) is the fixed cost of waste processing per ton and $W_{j}$ is the weight of waste material collected from component $j$ in tons.

Waste transport After processing, the waste materials are transported to either a landfill or the recycling depot. The transportation cost is calculated by multiplying the expected number of trucks required to transfer the waste materials by the fixed charge per truck shipment $\left(C_{\text {truck }}\right)$, i.e.

$C_{\mathrm{W} \text {-trans }}=\left\lceil\left(\sum_{j=1}^{n} W_{j}\right) / W_{\text {truck }}\right\rceil \times C_{\text {truck }}$,

where $W_{\text {truck }}$ represents the capacity of a truck in tons and $\lceil x\rceil$ rounds $x$ to the nearest larger integer.

Landfill We denote by $W_{j}^{\mathrm{R}}$ and $W_{j}^{\mathrm{NR}}$ the weight of, respectively, recyclable and non-recyclable materials collected from component $j$, where $W_{j}^{\mathrm{R}}+W_{j}^{\mathrm{NR}}=W_{j}$. The non-recyclable materials are disposed in a landfill, whose associated cost is calculated by multiplying the fixed landfill cost per ton $\left(C_{\text {landfill-unit }}\right)$ by the total weight of non-recyclable materials disposed, i.e.

$C_{\text {landfill }}=\sum_{j=1}^{n} W_{j}^{\mathrm{NR}} \times C_{\text {landfill-unit }}$.

Salvage value Salvage value is defined as the expected or estimated value of an asset at the end of its operational life. A large portion of the materials used in a wind turbine can be recycled (e.g. stainless steel). The salvage value of the items removed from an offshore wind farm depends on the type, quantity (i.e. volume or weight) and quality (or condition) of materials recycled. Let $k=1,2, \ldots, m$ represent the type of scrap material and $S V_{k}$ be the salvage value per ton of material of type $k$. The salvage (residual) value of the decommissioned components is expressed by the following formula:

$\mathrm{SV}=\sum_{j=1}^{n}\left[\sum_{k=1}^{m} W_{j k}^{\mathrm{R}} \times \mathrm{SV}_{k}\right]$

where

$\sum_{k=1}^{m} W_{j k}^{\mathrm{R}}=W_{j}^{\mathrm{R}}$

\subsubsection{Site clearance}

Following the decommissioning of the offshore wind farm, the whole site must be cleared in accordance with the approved regulations. Site clearance involves the removal of all assets of the offshore wind project. The cost associated with site clearance is calculated by multiplying the site area in square kilometres $(A)$ by the clearance cost per unit area $\left(C_{\text {SC-unit }}\right)$, i.e.

$C_{\mathrm{SC}}=A \times C_{\mathrm{SC}-\text { unit }}$

\subsubsection{Post-decommissioning monitoring}

Some of the offshore wind components (e.g. cables) may not be fully removed through the decommissioning process. For this reason, a post-decommissioning monitoring and management plan is required to identify and mitigate the risks that may be posed by remaining materials on the seabed. The cost of a post-decommissioning monitoring programme $\left(C_{\text {postM }}\right)$ is determined according to several factors such as scale, nature and the conditions of remains (Department of Energy and Climate Change DECC 2011). This cost is considered to be fixed in our analysis.

\section{Application}

In this section, the proposed whole life cost methodology is applied to an offshore wind farm consisting of 100 5-MW wind turbines. This baseline case has so far been studied in several articles (see Castro-Santos and Diaz-Casas 2014; Myhr et al. 2014; Howard 2012) and, therefore, it enables us to compare the results with previous research and validate the model. Moreover, some future projects are expected to follow this pattern as the size and capacity of wind farms continue to grow. In order to implement the model, some further aspects of the offshore wind project were identified and are presented briefly below:

- The offshore wind farm is planned to be built in a region located $40 \mathrm{~km}$ away from the coast and at 45-m water depth. The wind turbines have a 126-m rotor diameter and 100-m hub height with a jacket type of foundation. The distance to the onshore grid connection point is $10 \mathrm{~km}$.

- The seabed rental charges equal $2 \%$ of the wind farm's gross revenue and must be paid to the Crown Estate. The transmission charges are also paid to National Grid at an expected price of $£ 71.74$ per megawatt (Howard 2012). 
- The wind turbine foundations are expected to be supplied locally, whereas the wind turbine generators will be manufactured in the continent.

- The electrical system is composed of 33-kV array cables, a 500-MW HVAC transmission system and 220-kV export cables. The total length of array cable required is dependent on the offshore wind farm layout and often varies with the number of wind turbines and the power transmitted within the wind farm. As this paper does not aim to compare different layouts but to evaluate the influence of other key parameters, a layout is proposed and then the array cable length is calculated as a function of the number of wind turbines in the farm. In this layout design, the wind turbines are arranged in equal spacing (7.5 times the rotor diameter) between each other and the substation is placed in the middle of the wind farm. Figure 6 illustrates the layout considered for the offshore baseline wind farm.

The total length of array cables is estimated using the following equation (Fig. 7):

$L=1.6065 \times N_{\mathrm{WT}}-16.065$.

- The length of the export cables equals the distance between the installations and the shoreline, whereas the length of the onshore cables is the distance from land to the grid connection point.

- The installation of foundations and wind turbines is performed by multi-purpose self-propelled jack-up vessels. A heavy-lift crane is required for the installation of a substation. Some specialized cable-laying vessels are also used to lay the power transmission cables underwater.

- The O\&M activities are coordinated onshore, but two service vessels are always available to carry out offshore operations. Wind turbines undergo a preventive maintenance (PM) programme once a year, whereas the scheduled inspections of foundations and array cables are carried out every 5 years (Det Norske Veritas DNV 2010). CMS detectability level is set at $90 \%$. The costs associated with corrective maintenance are calculated according to the system's failure rate. The failure rate of wind turbines is assumed to be almost constant over the life cycle.

- The project's life cycle begins 5 years before the reference year and ends at 20 years of age. During the first 5 years of operation, all maintenance and insurance costs are paid by the warrantor or service contract provider. The cash flows over the life cycle of the project are distributed as given in Table 1. The interest rate is set at $9.24 \%$ as in Howard (2012).

- The offshore wind farm is decommissioned at the end of its service life, and no items will be left in situ. The waste materials are processed and transported to a scrapyard. Wind turbine tower, jacket and the met-tower are sold to be recycled by industry. About $60 \%$ of the nacelle and hub's materials can be reused whereas the recyclability for other items is $40 \%$. The array cables are deposited in a landfill.

- Data supporting the model were collected from various offshore wind datasets (e.g. WMEP, WindStats, Elforsk, etc.) and many available studies and industrial reports (e.g. Kaiser and Snyder 2012; Offshore Design Engineering Ltd. 2007; The Crown Estate 2010; Howard 2012; Dicorato et al. 2011; Tavner 2013; Shafiee and Dinmohammadi 2014; GL Garrad Hassan 2013; Department of Energy and Climate Change DECC 2011; Massachusetts Clean Energy 2010; Oceaneering International 2010; Renewable UK 2011; The Crown Estate 2011, 2012; Bjerkseter and Agotnes 2013; CastroSantos 2013; Metal 2014). Where information is not available, several surveys and interviews with equipment suppliers, construction companies, inspection agencies, etc. are conducted.

\section{Results and discussion}

In this section, the results obtained from our whole life cost model are presented and discussed. In order to validate the presented model, the results are compared to those experimental ones reported in the literature.

\subsection{WLC analysis results}

The LCC analysis is carried out in terms of three elements, namely CAPEX, OPEX and LCOE, enabling the decisionmakers to systematically compare the cost of different offshore wind projects. The CAPEX consists of the P\&C, P\&A and I\&C costs, while the OPEX only includes the O\&M costs. The LCOE also represents the net present value of the unit cost of electricity produced, which is calculated by taking into account all costs throughout the life of the project. The LCOE is determined using the following equation (Myhr et al. 2014):

$\mathrm{LCOE}=\sum_{t=1}^{N} C_{t} /(1+d)^{t} / \sum_{t=0}^{N} E_{t} /(1+d)^{t}$,

where $C_{t}$ and $E_{t}$ represent the cash flow and the yield output at time $t$, respectively.

Table 2 and Table 3 give the cost estimates obtained for, respectively, CAPEX and OPEX of the baseline offshore wind farm. The CAPEX and the annual OPEX are estimated at about $£ 1449 \mathrm{M}$ and $£ 79.25 \mathrm{M}$, respectively. This implies that the CAPEX and annual OPEX per unit installed power capacity equal, respectively, $£ 2898 \mathrm{k}$ and $£ 158.5 \mathrm{k}$. The relative 


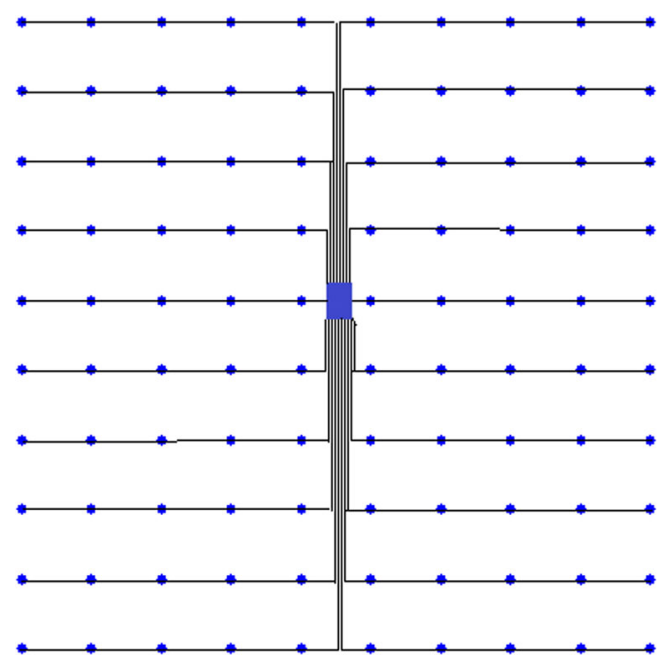

Fig. 6 Offshore wind farm layout for calculation of the array cable length

contributions of each cost driver to CAPEX and OPEX are also presented. As can be seen, the costs of procurement of wind turbines $\left(C_{\mathrm{WT}}\right)$ account for the largest proportion of the CAPEX (29\%), followed by foundation costs $(25.2 \%)$ and installation costs $(18.3 \%)$. On the other side, transmission charges $\left(C_{\text {transmission }}\right)$ account for the largest proportion of the OPEX (45.3\%), followed by proactive maintenance costs $(19.8 \%)$ and corrective maintenance costs $(16.9 \%)$. It was also indicated that I\&C insurance packages cost $1.4 \%$ of the CAPEX, whereas the operational insurance charges represent $9.2 \%$ of the OPEX.

The costs associated with the decommissioning and disposal phase of offshore wind facilities are reported in Table 4. As shown, the D\&D costs are estimated to be around $£ 202,370 \mathrm{k}$. The majority of these costs are related to component dismantling (93\%), while the waste disposal produces an income of $£ 13,926 \mathrm{k}$ through the sale of the scrap metal.

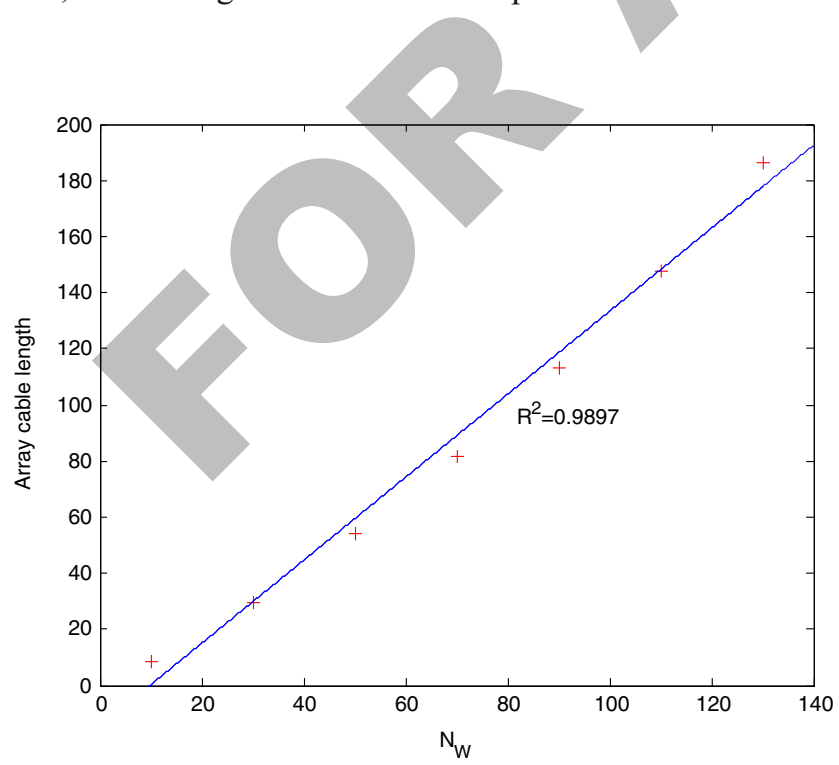

Fig. 7 The expected length of array cable
Table 1 Cash flow distribution over the life cycle (Howard 2012)

\begin{tabular}{llllllllll}
$\begin{array}{l}\text { Investment year } \\
\text { Operational year }\end{array}$ & 0 & 1 & 2 & 3 & 4 & 5 & $6-9$ & $10-24$ & 25 \\
Phase & \multicolumn{7}{l}{$\begin{array}{l}\text { Weighted investment distribution } \\
\text { Pover the years (\%) }\end{array}$} \\
\hline P\&C & 34 & 2 & 2 & 21.5 & 40 & 0.5 & 0 & 0 & 0 \\
P\&A & 0 & 0.1 & 16.3 & 37.3 & 43.4 & 2.9 & 0 & 0 & 0 \\
I\&C & 0 & 1.65 & 1.65 & 32.5 & 61.4 & 2.80 & 0 & 0 & 0 \\
O\&M & 0 & 0 & 0 & 0 & 0 & 0 & 0 & 100 & 0 \\
D\&D & 0 & 0 & 0 & 0 & 0 & 0 & 0 & 0 & 100 \\
\hline
\end{tabular}

The relative contribution of the costs associated with each phase of the project to the LCOE is shown in Fig. 8. Our results indicate that the costs incurred over the P\&A phase have the greatest impact on LCOE $(47 \%)$, followed by O\&M costs $(26 \%)$. Among five phases of the project's life cycle, the D\&D phase contributes the least percentage $(\sim 1 \%)$ to the LCOE.

When comparing the results obtained from our parametric LCC analysis model with other research, very minor differences are noted. This implies that our model has captured the general trend in the experimental data quite well. The results of the comparison are summarized as below:

a. Our proposed LCC analysis tool requires much less amount of input parameters compared to other tools available in the wind energy industry sector. Furthermore, the proposed model has the capability to precisely determine an interval or range of possible (or most likely) values of whole life cost for even larger offshore wind farms than the cases which were studied in the literature.

b. The estimation of total CAPEX for the project is very accurate and unbiased. The only difference between this estimate and the experimental results can be found in the calculated cost of procurement of wind turbines over the P\&A phase. Since some cost data used in this analysis were taken from a previous research in 2007 (Offshore Design Engineering Ltd. 2007) and then were discounted to their present values, the rising tendency in wind turbine prices may have led to a little underestimation of this cost. However, the analysis will be improved when our dataset is updated in the near future.

c. As the transmission charges were also included in our analysis, the estimation obtained for the OPEX in this study is slightly different from those reported in Tegen et al. (2013) and Myhr et al. (2014), but it is very close to the value obtained in Howard (2012).

d. Since only a very few number of studies have so far focused on cost analysis of offshore wind projects over the D\&D phase, our proposed model was validated through a survey of experts, managers and stakeholders of several European offshore wind farms. 
Table 2 Results for the CAPEX

\begin{tabular}{|c|c|c|c|c|}
\hline \multirow[t]{2}{*}{ Cost element } & \multicolumn{2}{|l|}{ Cost } & \multicolumn{2}{|c|}{$\%$ contribution } \\
\hline & Total $\left(\times 10^{3} £\right)$ & $\begin{array}{l}\text { Per MW installed } \\
(\mathfrak{£} / \mathrm{MW})\end{array}$ & Phase & CAPEX \\
\hline \multicolumn{5}{|l|}{$\mathrm{P} \& \mathrm{C}$} \\
\hline$C_{\text {projM }}$ & 41,724 & 83,448 & $20.6 \%$ & $2.9 \%$ \\
\hline$C_{\text {legal }}$ & $16,460.5$ & 32,921 & $8.1 \%$ & $1.1 \%$ \\
\hline$C_{\text {surveys }}$ & 18,889 & 37,778 & $9.3 \%$ & $1.3 \%$ \\
\hline$C_{\text {eng }}$ & 1127.5 & 2255 & $0.6 \%$ & $0.1 \%$ \\
\hline$C_{\text {contingency }}$ & 124,618 & 249,236 & $61.4 \%$ & $8.6 \%$ \\
\hline$C_{\mathrm{P} \& \mathrm{C}}$ & 202,819 & 405,638 & $100.0^{\circ}$ & $14.0 \%$ \\
\hline \multicolumn{5}{|l|}{ P\&A } \\
\hline$C_{\mathrm{WT}}$ & $420,265.5$ & 840,531 & $44.5 \%$ & $29.0 \%$ \\
\hline$C_{\mathrm{SS}}$ & 365,465 & 730,930 & $38.7 \%$ & $25.2 \%$ \\
\hline$C_{\mathrm{PTS}}$ & $156,478.5$ & 312,957 & $16.6 \%$ & $10.8 \%$ \\
\hline$C_{\text {monitoring }}$ & 2472 & 4944 & $0.2 \%$ & $0.2 \%$ \\
\hline$C_{\mathrm{P} \& \mathrm{~A}}$ & 944,681 & $1,889,362$ & $100 \%$ & $65.2 \%$ \\
\hline \multicolumn{5}{|l|}{$\mathrm{I} \& \mathrm{C}$} \\
\hline$C_{\mathrm{I} \& \mathrm{C}-\text { port }}$ & 14,689 & 29,378 & $4.9 \%$ & $1.0 \%$ \\
\hline$C_{\mathrm{I} \& \mathrm{C}-\mathrm{comp}}$ & 265,769 & 531,538 & $88.1 \%$ & $18.3 \%$ \\
\hline$C_{\text {comm }}$ & 240 & 480 & $0.1 \%$ & $0.1 \%$ \\
\hline$C_{\mathrm{I} \& \mathrm{C}-\mathrm{ins}}$ & 20,800 & 41,600 & $6.9 \%$ & $1.4 \%$ \\
\hline$C_{\mathrm{I} \& \mathrm{C}}$ & 301,498 & 602,996 & $100 \%$ & $20.8 \%$ \\
\hline CAPEX & $1,448,998$ & $2,897,996$ & & \\
\hline
\end{tabular}

\subsection{Sensitivity analysis}

sensitivity analysis to confirm the validity of the proposed model.

A sensitivity analysis is conducted to evaluate the impact of some key variables, e.g. capacity of offshore wind farm, site location, interest rate and the quality of fault detection on LCC of the offshore wind project. To this aim, at each iteration of the analysis, only one parameter is changed while the other parameters remain unchanged. In what follows, we present the results from the

\subsubsection{Installed capacity of offshore wind farm}

The installed capacity of a wind farm represents the total capacity of all wind turbines installed in the wind farm. This capacity depends not only on the number of wind turbines but also on their power rating. The installed power capacity
Table 3 Results for the annual OPEX

\begin{tabular}{llll}
\hline & \multicolumn{2}{l}{ Cost } & \% contribution \\
\cline { 2 - 4 } Cost element & Total $\left(\times 10^{3} £\right)$ & $\begin{array}{l}\text { Per MW installed } \\
(\mathfrak{£} / \mathrm{MW})\end{array}$ & OPEX \\
\hline O\&M & & & \\
$C_{\text {rent }}$ & 1947.5 & 3895 & $2.5 \%$ \\
$C_{\text {O\&M-ins }}$ & 7280 & 14,560 & $9.2 \%$ \\
$C_{\text {transmission }}$ & 35,895 & 71,790 & $45.3 \%$ \\
$C_{\mathrm{M}-\text {-indirect }}$ & 5033.7 & 10,067 & $6.3 \%$ \\
$C_{\text {ProM }}$ & $15,690.6$ & 31,381 & $19.8 \%$ \\
$C_{\mathrm{CM}}$ & $13,394.7$ & 26,789 & $16.9 \%$ \\
$C_{\mathrm{O \& M}}$ & $79,241.5$ & 158,483 & $100 \%$ \\
OPEX & $79,241.5$ & 158,483 & \\
\hline
\end{tabular}


Table 4 Results for the D\&D costs

\begin{tabular}{llll}
\hline Cost element & Cost & \multirow{2}{*}{$\%$ contribution } \\
\cline { 2 - 3 } & Total $\left(\times 10^{3} £\right)$ & $\begin{array}{l}\text { Per MW } \\
\text { installed (£/MW) }\end{array}$ & \multicolumn{1}{c}{$C_{\mathrm{D} \& \mathrm{D}}$} \\
\hline D\&D & & & \\
$C_{\mathrm{D \& D}-\text { port }}$ & 20,892 & 41,784 & $10.3 \%$ \\
$C_{\text {remov }}$ & $188,173.5$ & 376,347 & $93.0 \%$ \\
$C_{\mathrm{WM}}$ & $-13,926$ & $-27,852$ & $-6.9 \%$ \\
$C_{\mathrm{SC}}$ & 3615 & 7230 & $1.8 \%$ \\
$C_{\text {postM }}$ & 3615 & 7230 & $1.8 \%$ \\
$C_{\mathrm{D} \& \mathrm{D}}$ & $202,369.5$ & 404,739 & $100 \%$ \\
\hline
\end{tabular}

of a wind farm with multiple wind turbines of the same type is determined by the number of wind turbines multiplied by the rated power of each one, i.e.

$\mathrm{IC}=\mathrm{PR} \times N_{\mathrm{WT}}$.

Although increasing the power capacity of a wind farm (either through increasing the number of wind turbines or by increasing the individual power ratings) certainly increases the overall cost, it will considerably reduce the LCC per unit installed capacity. The effect of the number of wind turbines on the LCOE is illustrated in Fig. 9. As shown, the LCOE (£/MWh) decreases as the number of wind turbines in the offshore wind farm increases. This is because the fixed costs are spread over a larger number of wind turbines, leading to a lower cost per unit of electricity output. The effect of the number of wind turbines on LCOE is more drastic for small- and medium-scale offshore wind farms than for large-scale ones. The LCOE converges to a value around 118.3 £/MWh when the installed power capacity of an offshore wind farm reaches $300 \mathrm{MW}$.

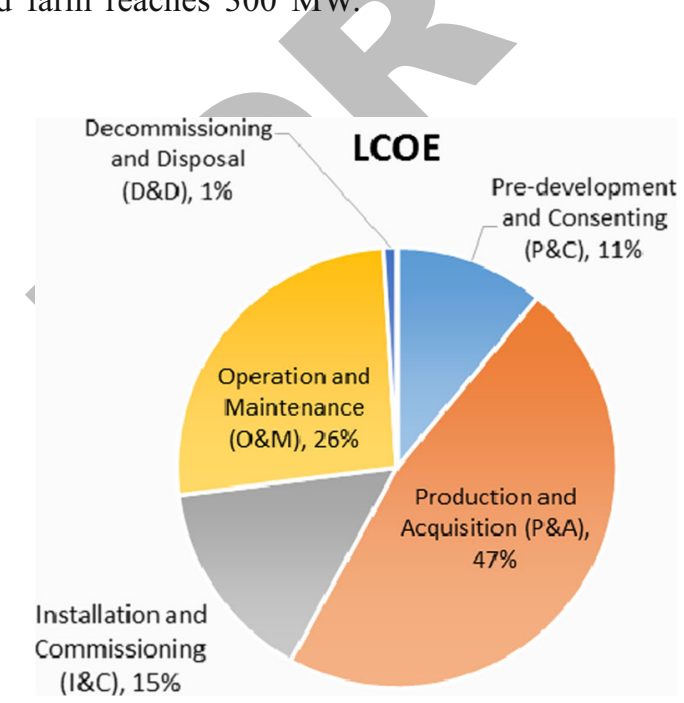

Fig. 8 Contribution of different life cycle phases to LCOE

\subsubsection{Site location}

Nowadays, many offshore wind farms are being built in remote deep-sea locations. The location of the wind farm site and the position of wind turbines have a strong influence on the project's LCC. Our analysis shows that both CAPEX and OPEX of the offshore wind farm increase dramatically with increasing the distance from sea coastline. The distance of a wind farm from shore affects the length of export cables, the duration of the installation and maintenance tasks and the total downtime of wind turbines. The LCOE will increase about $11 \%$ if the distance of the offshore wind farm from shore is doubled.

\subsubsection{Interest rate}

The interest rate plays an important role in the whole life cost analysis of offshore wind projects. Our results indicate that $1 \%$ reduction in interest rate would bring the LCOE down by around $5.3 \%$.

\subsubsection{Quality of fault detection}

Improving the fault detection quality (i.e. reducing the rate of false alarms) is recognized as a cost-effective solution to reduce the O\&M costs of a wind turbine. Our results indicate that the LCOE can be reduced by $0.24 \%$ if the fault detection capability of the wind turbines improves by $10 \%$.

\section{Conclusions and topics for future research}

The development of a realistic and accurate method for life cycle cost (LCC) analysis of large-scale offshore wind farms is a very complex task. In this paper, a parametric whole life

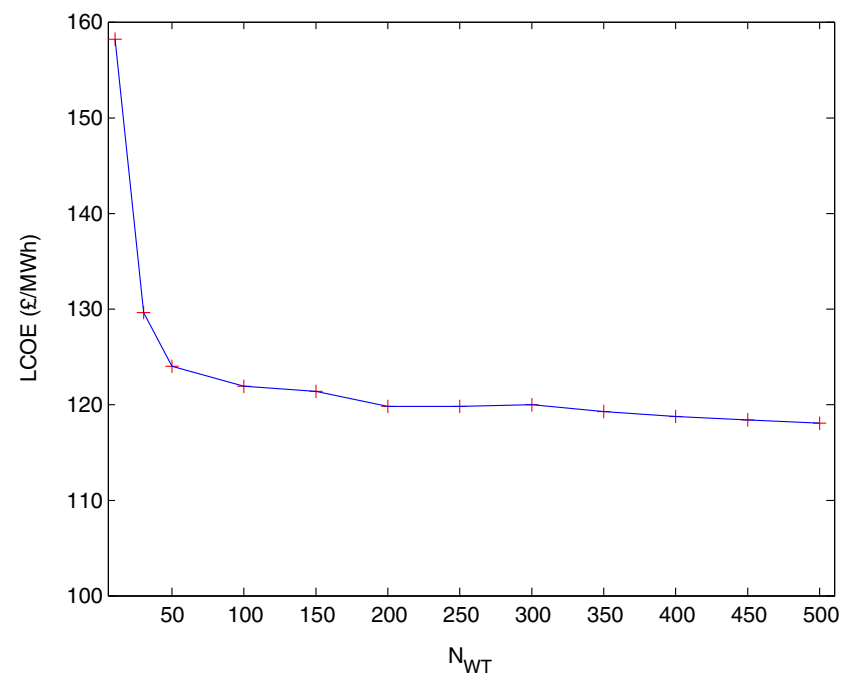

Fig. 9 Effect of number of wind turbines on LCOE 
cost (WLC) analysis model was developed to identify the key cost drivers of offshore wind projects. The proposed model is based on a combined multivariate regression/neural network approach in which the cost experience of completed/ongoing projects provides a baseline for estimating the costs of future projects. A cost breakdown structure (CBS) was presented to identify various cost elements involved in five phases of offshore wind projects, namely pre-development and consenting $(\mathrm{P} \& \mathrm{C})$, production and acquisition $(\mathrm{P} \& \mathrm{~A})$, installation and commissioning (I\&C), operation and maintenance (O\&M) and decommissioning and disposal (D\&D). A database/ spreadsheet was also built for each unit cost, and several mathematical tools were used to evaluate all costs incurred during the life of the project.

Data availability is known as one of the biggest limitations of parametric life cycle cost models for offshore wind farms. In order to make a highly accurate estimate of the life cycle cost in offshore wind projects, a database of reliable performance data is required. The data supporting this research were gathered from the literature and several offshore wind databases, but where some information was unavailable, the data were collected through surveying and interviewing the wind energy experts. Our results indicated that the capital cost of wind turbines and support structures as well as the costs associated with installation account for the largest portion of overall cost, followed by the O\&M costs. The installed capacity of a wind farm, the distance from shore, and the fault detection capability of a condition monitoring system were identified as parameters with significant influence on levelized cost of energy (LCOE). Since the service lifetime of a wind farm is relatively long, a small change in interest rate leads to a large variation in the project's total cost. The presented models not only assist stakeholders in evaluating the performance of ongoing projects but also help the wind farm developers to reduce their costs in the medium-long term.

This study can be extended in many directions. The influence of water depth on the CAPEX/OPEX was not investigated due to lack of data. Besides this, the load factor, wake losses and electric losses were assumed to be constant throughout the analysis. The proposed model will be extended in the nearest future by taking into account more of the factors which are known to affect the cost of electricity generation from offshore wind (e.g. harshness of weather conditions, variations of wind turbine loads).

Acknowledgments The authors gratefully acknowledge the support provided by the owners of several European offshore wind farms during field visits and data collection.

\section{References}

Bjerkseter C, Agotnes A (2013) Levelised costs of energy for offshore floating wind turbine concepts. Department of Mathematical Sciences and Technology. Norwegian University of Life Sciences, Norway

Castro-Santos L (2013) Metodología para la evaluación económica de parques eólicos offshore flotantes a través del análisis del coste de las fases de su ciclo de vida. PhD Thesis. Universidad de la Coruña, La Coruña Spain

Castro-Santos L, Diaz-Casas V (2014) Life-cycle cost analysis of floating offshore wind farms. Renew Energy 66:41-48

Davidsson S, Höök M, Wall G (2012) A review of life cycle assessments on wind energy systems. Int J Life Cycle Assess 17:729-742

Department of Energy \& Climate Change (DECC) (2011) Decommissioning of offshore renewable energy installations under the Energy Act 2004. URN 10D/1025, DECC, London, United Kingdom

Det Norske Veritas (DNV) (2010) Design of offshore wind turbine structures. DNV-OS-J101, Norway

Dicorato M, Forte G, Pisani M, Trovato M (2011) Guidelines for assessment of investment cost for offshore wind generation. Renew Energy 36(8):2043-2051

Dinmohammadi F, Shafiee M (2013) A fuzzy-FMEA risk assessment approach for offshore wind turbines, International Journal of Prognostics and Health Management, 4:59-68.

EWEA (European Wind Energy Association) (2015) The European offshore wind industry - key trends and statistics. Available online: http:/www.ewea.org

Fuller SK, Peterson SR (1996) Life cycle costing manual for the federal energy management program. U.S. Department of Energy, Washington, USA

Garrad Hassan GL (2013) A guide to UK offshore wind operations and maintenance. Scottish Enterprise and The Crown Estate, UK

Howard R (2012) Offshore wind cost reduction pathways project—simple levelised cost of energy model. The Crown Estate, London, UK

IRENA (International Renewable Energy Agency) (2012) Renewable energy cost analysis: wind power. Available at: https://www.irena.org

Kaiser MJ, Snyder B (2012) Offshore wind energy cost modelling: installation and decommissioning. Springer, London, UK

Krohn S, Morthorst P-E, Awerbuch S (2009) The economics of wind energy. European Wind Energy Association (EWEA), Belgium

Levitt AC, Kempton W, Smith AP, Musial W, Firestone J (2011) Pricing offshore wind power. Energ Policy 39(10):6408-6421

Madariaga A, de Alegría IM, Martín JL, Eguía P, Ceballos S (2012) Current facts about offshore wind farms. Renew Sust Energ Rev 16(5):3105-3116

Maples B, Saur G, Hand M (2013) Installation, operation, and maintenance strategies to reduce the cost of offshore wind energy. NREL/TP-5000-57403. National Renewable Energy Laboratory, Colorado, USA

Márquez FPG, Tobias AM, Pérez JMP, Papaelias M (2012) Condition monitoring of wind turbines: techniques and methods. Renew Energ 46:169-178

Massachusetts Clean Energy Center (2010) Port and infrastructure analysis for offshore wind energy development. Boston, USA

Metal Prices (2014) Metal index: steel and iron. Available at: http://www. metalprices.com/p/metal index (accessed 18th May 2015)

Myhr A, Bjerkseter C, Ågotnes A, Nygaard TA (2014) Levelised cost of energy for offshore floating wind turbines in a life cycle perspective. Renew Energ 66:714-728

Nielsen P (2003) Offshore wind energy projects feasibility study guidelines. SEAWIND-Altener project 4.1030/Z/01-103/2001, Ver. 3.0. Aalborg, Denmark 
Nilsson J, Bertling L (2007) Maintenance management of wind power systems using condition monitoring systems - life cycle cost analysis for two case studies. IEEE T Energy Conver 22(1):223-229

Nordahl M (2011) The development of a life cycle cost model for an offshore wind farm. Chalmers University of Technology, Gothenburg, Sweden

Oceaneering International (2010) ROV services rate schedule UK \& Europe. Aberdeen, UK

Offshore Design Engineering Ltd. (2007) Study of the costs of offshore wind generation. Renewables Advisory Board and Department of Trade and Industry, UK

Renewable UK (2011) Offshore wind: forecasts of future costs and benefits. UK

Shafiee M (2015a) Maintenance logistics organization for offshore wind energy: current progress and future perspectives. Renew Energ 77: 182-193

Shafiee M (2015b) Maintenance strategy selection problem: an MCDM overview. J Qual Maint Eng 21(4):378-402

Shafiee M (2015c) A fuzzy analytic network process model to mitigate the risks associated with offshore wind farms, Expert Systems With Applications, 42(4):2143-2152

Shafiee M, Dinmohammadi F (2014) An FMEA-based risk assessment approach for wind turbine systems: a comparative study of onshore and offshore. Energies 7(2):619-642
Shafiee M, Finkelstein M (2015) An optimal age-based group maintenance policy for multi-unit degrading systems. Reliab Eng Syst Saf 134:230-238

Tavner P (2013) Offshore wind turbines: reliability, availability and maintenance. The Institution of Engineering and Technology, London, UK

Tegen S, Lantz E, Hand M, Maples B, Smith A, Schwabe P (2013) Cost of wind energy review. NREL/TP-5000-56266. National Renewable Energy Laboratory (NREL), Colorado USA

The Crown Estate (2010) A guide to an offshore wind farm. London, UK

The Crown Estate (2011) Offshore transmission network feasibility study. London, UK

The Crown Estate (2012) Offshore wind cost reduction: pathways study. Finance work stream, London, UK

Thomson RC, Harrison GP (2015) Life cycle costs and carbon emissions of offshore wind power. Available at: www. climatexchange.org.uk

U.S. Energy Information Administration (2014) Levelized cost and levelized avoided cost of new generation resources in the annual energy outlook. Available on: http://www.eia.gov

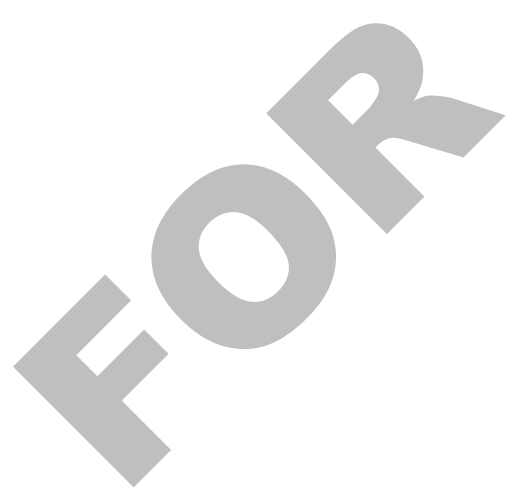

